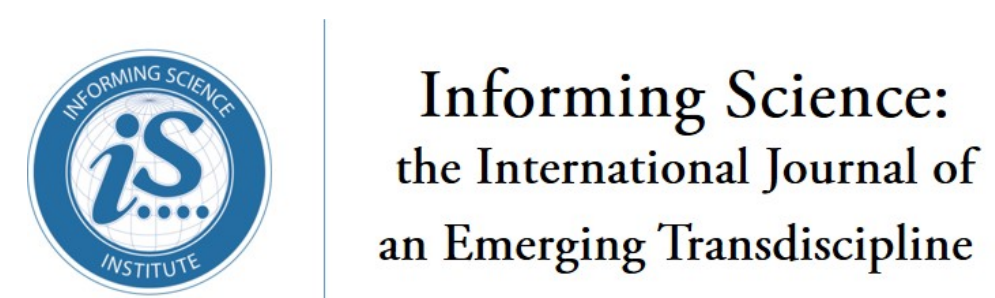

An Official Publication

of the Informing Science Institute

InformingScience.org

Inform.nu

Volume 23, 2020

\title{
Why People Perceive Messages Differently: THE THEORY OF COGNITIVE MAPPING
}

Eli B. Cohen

Informing Science Institute,

EliBCohen@InformingScience.org

Santa Rosa, CA, USA

\section{ABSTRACT}

Aim/Purpose

The paper introduces new concepts including cognitive mapping, cognitive message processing, and message resonance.

Background

This paper draws upon philosophy, psychology, physiology, communications, and introspection to develop the theory of cognitive mapping.

Methodology

Theory development.

Contribution

The theory offers new ways to conceptualize the informing process.

Findings

Cognitive mapping has a far-reaching explanatory power on message resonance.

Recommendations

for Researchers

The theory of cognitive mapping offers a new conceptualization for those ex-

Future Research ploring the informing process that is ripe for exploration and theory testing.

This paper forms a building block toward the development of a fuller model of the informing process.

Keywords

cognitive mapping, cognitive message processing, informing science, message resonance, constructed reality

\section{INTRODUCTION}

Why do different people perceive messages differently from one another? This paper searches for an answer to the question. Here is an example where different people (reporters and editors) saw the same event with different eyes.

A journalist, NBC White House reporter Peter Alexander, asked President Trump a question about the US response to a crisis. The question upset Trump. Here is the interchange from March 2020:

Reporter: "What do you say to Americans watching you right now who are scared" [of the coronavirus outbreak]?

Trump: “I'd say you are a terrible reporter. I think that's a very nasty question, and I think that's a very bad signal that you're putting out to the American people. The American people

Accepting Editors Scott Lloyd \& Grandon Gill | Received: April 22, 2020 | Revised: July 28, 2020 | Accepted: September 1, 2020.

Cite as: Cohen, E. B. (2020). Why people perceive messages differently: The theory of cognitive mapping. Informing Science: The International Journal of an Emerging Transdiscipline, 23, 89-106. https://doi.org/10.28945/4629

(CC BY-NC 4.0) This article is licensed to you under a Creative Commons Attribution-NonCommercial 4.0 International License. When you copy and redistribute this paper in full or in part, you need to provide proper attribution to it to ensure that others can later locate this work (and to ensure that others do not accuse you of plagiarism). You may (and we encourage you to) adapt, remix, transform, and build upon the material for any non-commercial purposes. This license does not permit you to use this material for commercial purposes. 
are looking for answers and hope, and you're doing sensationalism, the same with NBC and Comcast -- I don't call it Comcast, I call it Con-cast -- for whom you work. Let me tell you something. That's really bad reporting. You should get back to reporting instead of sensationalism. You ought to be ashamed of yourself." (Hains, 2020)

All the reporters observed the same event, yet they reported it from different perspectives, as evidenced by the headlines of their reports. Table 1 shows headlines about the exchange [with select words bolded for emphasis] as disseminated by five different news outlets. These and other media outlets were rated on their political leanings on a scale from far left-right to far-right by two independent rating websites. We see that right-leaning news outlets perceive Trump's response as positively as sparring or scolding while left-leaning news outlets see it in terms of histrionics, rants, and tantrums.

Table 1. Headlines rely on the Cognitive Map of the headline writer

\begin{tabular}{|c|c|c|}
\hline Outlet & Headline & $\begin{array}{l}\text { Rating by Media Bias Fact Check (MBFC) (top) } \\
\text { and AllSides.com (bottom) } \\
\text { Note that left-center rating on MBFC corresponds to } \\
\text { lean left on AllSides }\end{array}$ \\
\hline CNN: & $\begin{array}{l}\text { Trump Rants at } \\
\text { Reporter }\end{array}$ & \begin{tabular}{|l} 
Bias: Left \\
Lean Left
\end{tabular} \\
\hline Guardian News: & $\begin{array}{l}\text { Trump Throws } \\
\text { Tantrum }\end{array}$ & $\begin{array}{l}\text { Bias: Left-Center } \\
\text { Lean Left }\end{array}$ \\
\hline Real Clear Politics: & $\begin{array}{l}\text { Trump Upbraids } \\
{[\text { Hains }]}\end{array}$ & $\begin{array}{l}\text { Bias: Right-Center } \\
\text { Center }\end{array}$ \\
\hline The Telegraph: & $\begin{array}{l}\text { Trump Clashes } \\
\text { with Reporter }\end{array}$ & $\begin{array}{l}\text { Bias: Right } \\
\text { Lean Right }\end{array}$ \\
\hline Fox: & $\begin{array}{l}\text { Trump Spars with } \\
\text { Reporter }\end{array}$ & $\begin{array}{l}\text { Bias: Right } \\
\text { Lean Right }\end{array}$ \\
\hline \multicolumn{3}{|c|}{$\begin{array}{l}\text { Sources: https://mediabiasfactcheck.com/ } \\
\text { www.allsides.com/media-bias/media-bias-ratings \#ratings }\end{array}$} \\
\hline
\end{tabular}

This paper seeks a theory to explain why this single event was reported using such diverse headlines. It is not looking at why Trump responded as he did to the question ${ }^{1}$.

1 Some may argue that Trump perceived the reporter's question as an attack because of the reporter's prior reporting. This interchange is similar to his response on November 9, 2018 to a question by CNN reporter Abby Philip; see "What a stupid question that is...You ask a lot of stupid questions" https://youtu.be/XK3PjUKXDhc What a STUPID Question - President slams Abby Philip of CNN posted by Nameless Dopey on Dec. 25, 2018 ) An informal search for those who posted the video clip on websites use wording in its headlines including "Trump slams" and he "lambasts" the journalist (https://www.yenisafak.com/en/video-gallery/news/trump-chides-cnnreporter-what-a-stupid-question-2198065)) 
This event and similar ones occur daily. This paper endeavors to explain this phenomenon in terms of a concept we term Cognitive Mapping Theory. (The term is an expansion of the concept described in Eden, 1988, not as the term is used in a different context to theorize spatial navigation.)

\section{BACKGROUND}

How is it that different people can observe the same phenomenon but "see" it differently? Isn't there a single reality? The paper first explores this question. Then the paper explores the idea of a nomological network and other elements of background before proceeding to bring together these background concepts into a theory.

\section{IS REALITY A REALITY? HOW SCIENCE AND REAL-LIFE DIFFER}

Many trained in the sciences learn to think of reality as a singularity. The scientific approach to discovery assumes that reality is one thing, experienced by many as a shared reality (Rossignac-Milon et al., 2020). Parts of it can be verified as true empirically through replicable experimentation. Scientists design experiments to reveal or uncover artifacts that can be tested to validate the experiments' hypotheses that are as abstractions of reality. (See Figure 1.) This idea of a scientific reality forms the foundation of the hard sciences, such as physics and astronomy. The scientific approach acknowledges that reality is greater than what we can now verify empirically. Science relies on observables to test our theories of reality. As we shall see, the nomological network provides a way for science to test hypotheses that are not directly observable.
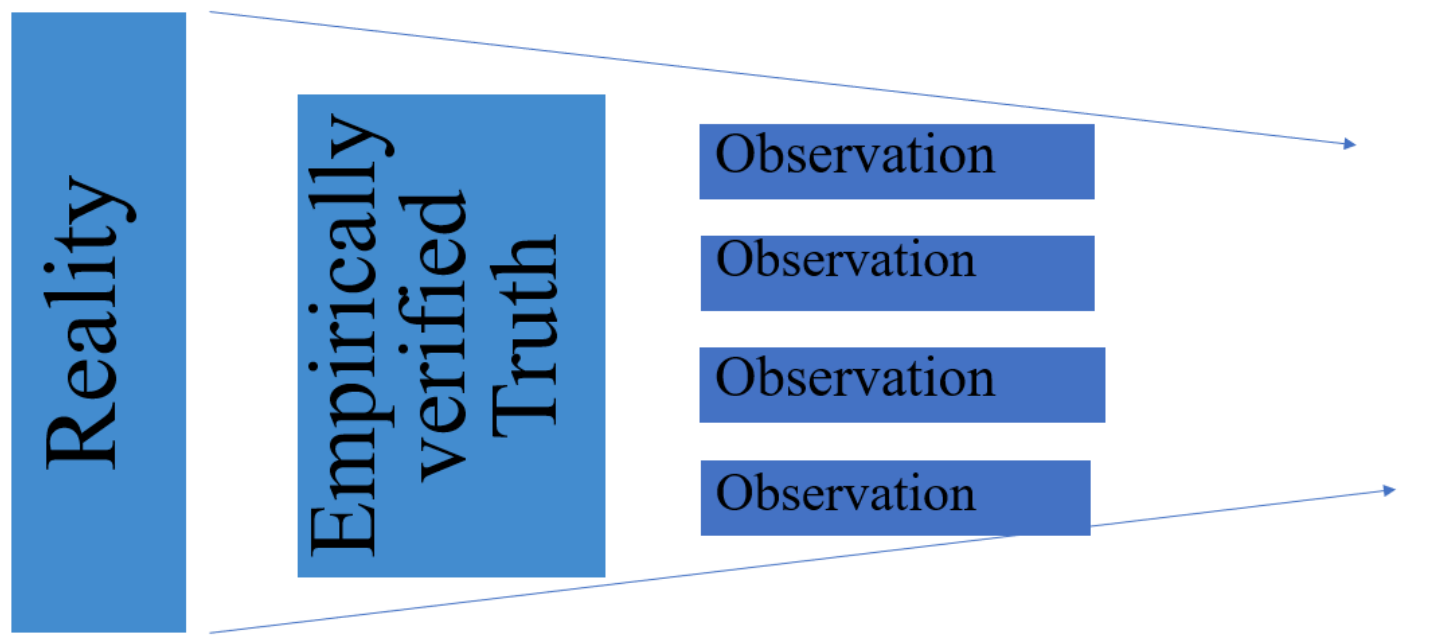

Figure 1. Science assumes a shared agreement on reality

\section{NOMOLOGICAL NETWORK}

Hard science, in many situations such as astronomy, needs to test theories of reality indirectly, what I call understanding reality through the veil of observations. The formal term for this is constructed reality. The term construct comes from the philosophy of science. Real objects exist in the real world and are observable. In contrast, constructs are ideal objects that exist only within one's mind.

Constructs and construct validity have been applied as well to the soft sciences, such as psychology. Building on the work by McCorquodale and Meehl (1948), Cronbach and Meehl in 1955 refined the idea of construct validity. Figure 2 illustrates the relationships among constructs and observables. idea. For psychology, the question was, "How can we model what is in a person's mind?" When a subject takes a psychological test, any interpretation of the test's results requires making assumptions about some unobservable elements of the subject's psyche. We can observe the questionnaire 
answers, for example, to an anxiety profile, but we cannot see inside subjects' brains to determine their levels of anxiety. The unobservable elements are called psychological constructs.

When dealing with human minds, then, one need no longer expect that all people share a common perception of reality.

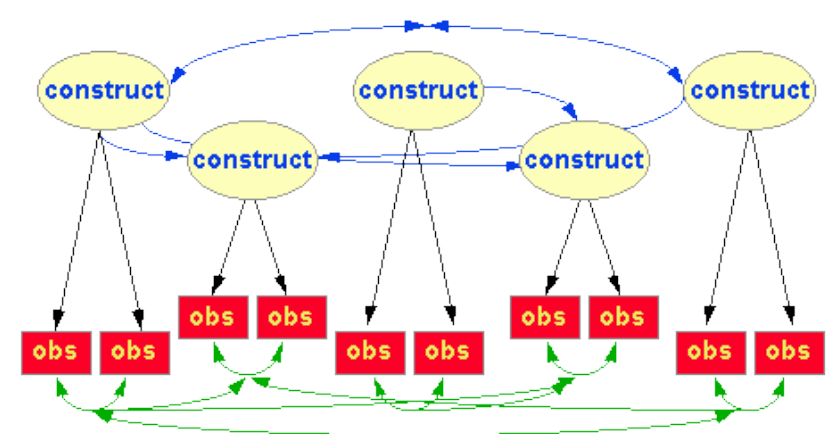

Figure 2. The nomological network is a representation of constructs, their observable manifestations, and the interrelationships among and between them (Trochim, 2020)

\section{What is said and what is heard}

At the start of this paper, using the presidential press conference example, we noted an instance where a single message is "observed" differently by different people. Another situation by which a single message becomes corrupted is through repeated retransmissions as described here.

Single Message Reported Multiple Times: Messages get Mangled in Translation. Consider the children's game of Telephone. In the game, children form a line, and the first whispers a message into the ear of the second who attempts to whisper the same into the next child's ear. By the end of the line, the original message of "a guppy in a shark tank" might be rendered "small fish in a lake." The translation is not from one language to another but from one person's understanding of the message into the next. Each translation introduces fresh errors that accumulate.

Message corruption through successive retransmission is more serious than a game. Consider the profound consequence of the message getting confused by mental translation by business staff having different job types. The customer tells the salesman that she wants a tire swing. Sales relate this message to the designer who conveys the resultant design to engineering. By the time the installer installs the tire swing (see Figure 3), message garbling becomes apparent.

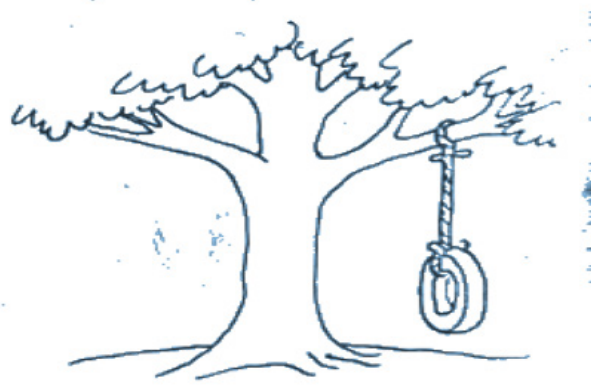

WHAT THE CUSTOMER WANTED!!!

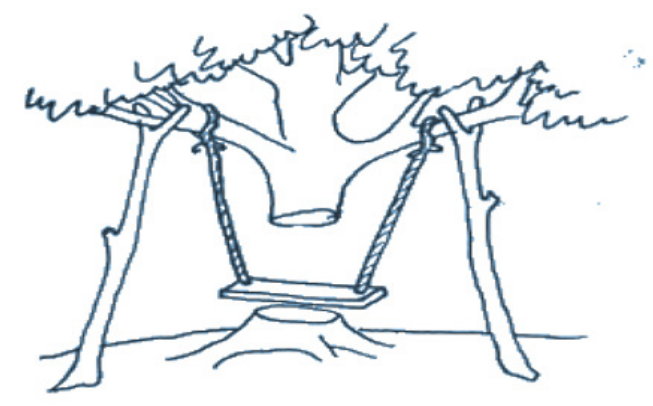

AS FIELD SERVICE INSTALLED IT

Figure 3. Adapted from Tree Swing picture from 1970s.

("Tree swing cartoon pictures," n.d.) 
The essence of the problem is that what is said and what is heard are not identical. Between hearing and saying, some mental translation takes place. That cognitive process and its consequences for informing are what this paper explores.

\section{Cognitive Limitations: Human brains have capacity and processing limitations}

People have limited capacities for perceiving information and processing information. The paper now explores a few of these.

Cognitive Processing and Bias. Bias influences how people react to messages. There are many types of cognitive bias. Several researchers of the informing process (Gill \& Hoppe, 2009, and Jamieson \& Hyland, 2006, for example) acknowledge bias in their models. One example of bias, confirmation bias, recognizes that we humans tend to value more messages that confirm our preexisting beliefs and discount others. We mention confirmation bias at the start since the idea of preexisting beliefs forms the foundation of the theory of cognitive mapping.

But confirmation bias is just one of many dozens of psychological biases impacting human judgment identified by researchers. Figure 4 illustrates and briefly defines a few of these. Figure 5 shows that bias, which seems like irrational processing by the human brain, may be based on an evolution of thinking tradeoffs that proved helpful for human survival.

Perception and Attention Limitations. Above the paper looked at bias. Humans also have other limitations. One obvious limitation to human perception is our limited ability to perceive wavelength. We cannot see as well as eagles, hear as well as bats or dolphins, detect heat as well as bats and vipers. Similarly, unlike sharks and bumblebees, we are oblivious to the presence of electricity (Yanes, 2017). And hummingbirds see ultraviolet light that is invisible to humans (Holtz, 2020).

Not only are we humans limited in what we can perceive, but we also have limits to what we attend; that is, we have limited attentional capacity.

The design of our brains cannot deal with the glut of information and messages present, particularly with the increase over the most recent decades. We live in a time of "data smog" and "information glut" (Shenk, 1997). On television, instead of just three or four channels, we can choose from hundreds. On the Internet, the number of websites has swelled from only one a mere thirty years ago to over 1.7 trillion (Liedke, 2020).

We, humans, have limited attention capacity, so we can attend only to so much. Our brains select to what we attend and to what aspects of reality we do not attend. Selective attention illustrates why people did not see the gorilla on the basketball court in the experiment by Simons and Chabris (1999).

Memory Limitations. Over 60 years ago, George Miller (1956) theorized on the constraints to the human capacity to process and remember information. Since then, the limitations and fragility of memory have received considerable study. We remember only a tiny percent of what we perceive. Even worse, what we do recall is, at times, inaccurate or manufactured memories; see, for example, Robbins (2014). 


\section{COGNITIVE BIASES THAT SCREW UP YOUR DECISIONS}

\section{Anchoring bias.}

People are over-reliant on the first piece of information they hear. In a salary negotiation, reasonable possibilities in reasonable possibiliti
each person's mind.

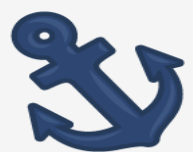

5. Choice-supportive bias When you choose something, you tend to feel positive abou Like how you think your dog is awesome - even if it bites people every once in a while.

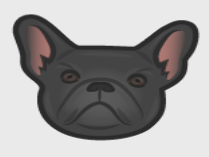

9. Information bias.

The tendency to seek information when it does not is not always better. With less information, people can often make more accurate predictions.

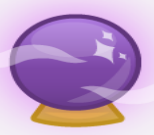

\section{Placebo effect.}

When simply believing that something will have a certain that effect. In medicine, people given fake pills often experien the same physiological effects as people given the real thing.

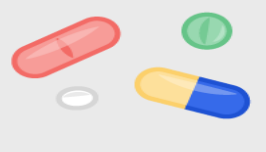

17. Selective perception. Allowing our expectations to influence how we perceive the world. An experiment involving a football game between studen that one team saw the opposing team commit more infractions.

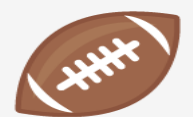

\section{Availability heuristic.}

People overestimate the

importance of information that

is available to them. A person

might argue that smoking is not

unhealthy because they know

someone who lived to 100 and

smoked three packs a day.

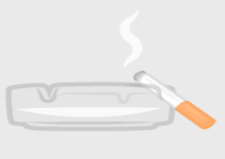

6. Clustering illusion.

This is the tendency to see

It is key to various events.

fallacies, like the idea that red

is more or less likely to turn up

on a roulette table after a string of reds.

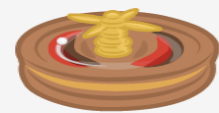

10. Ostrich effect.

The decision to ignore dangerous or negative information by "burying"
one's head in the sand, like an ostrich. Research suggests that investors check the value of their holdings significantly less often during bad markets.

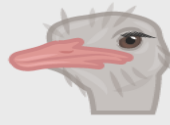

14. Pro-innovation bias. When a proponent of an innovation tends to overvalue its limitations. Sound familiar. Silicon Valley?

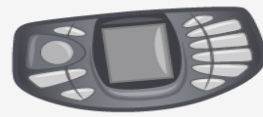

\section{Stereotyping.}

Expecting a group or person to have certain qualities without having real information about the person. It allows us to quickly identify strangers as tend to overuse and abuse it

\section{Bandwagon effect.}

The probability of one person adopting a belief increases based on the number of people whowerful form of groupthink and is reason why meetings and is reason why meetings

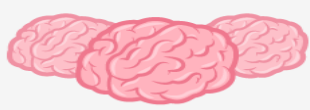

\section{Confirmation bias.}

We tend to listen only to information that confirms our preconceptions - one of the many reasons it's so hard to about climate change.

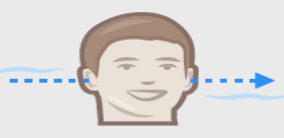

11. Outcome bias.

Judging a decision based on the outcome - rather than how
exactly the decision was made in the moment. Just because you won a lot in Vegas doesn mean gambling your money

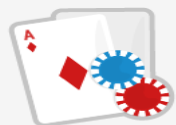

\section{Recency.}

The tendency to weigh the latest information more heavily than older data. Investors often the way it looks today and make unwise decisions.

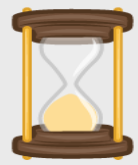

19. Survivorship bias.

An error that comes from focusing only on survivin examples, causing us to misjudge a situation. For being an entrepreneur is easy because we haven't heard of all those who failed.
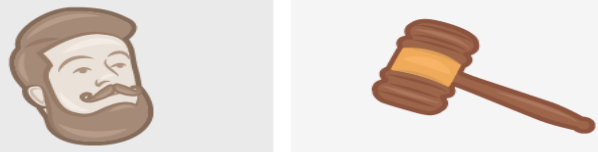

\section{Blind-spot bias.}

Failing to recognize your own cognitive biases is a bias in itself. People notice cognitive more in others than in themselves.

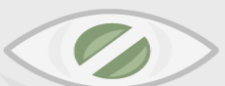

\section{Conservatism bias.} Where people favor prior
evidence over new evidence or information that has emerged. People were slow to accep that the Earth was round because they maintained their
earlier understanding that the planet was flat.

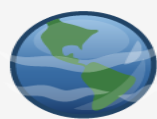

\section{Overconfidence.}

Some of us are too confident about our abilities, and this causes us to take greater risks more prone to this bias than laypeople, since they are more convinced that they are right.

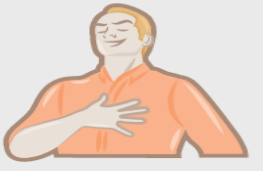

16. Salience.

Our tendency to focus on the most easily recognizable When you think about dying you might worry about being mauled by a lion, as opposed to what is statistically more likely, like dyin in a car accident.

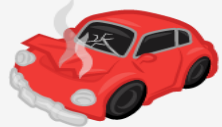

\section{Zero-risk bias.}

Sociologists have found that we love certainty - even if it's rounterproductive. Eliminating chance of harm being coused.

Figure 4. 20 Cognitive biases (Lebowitz \& Lee, 2015, used with permission) 


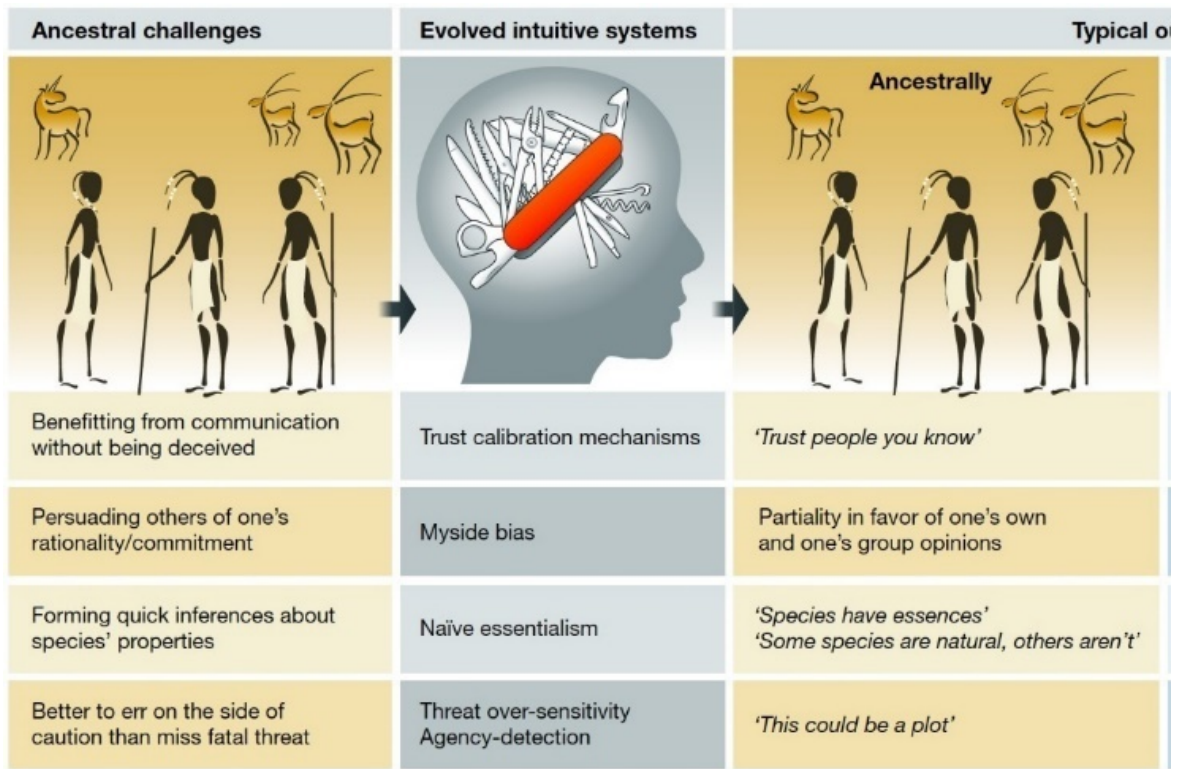

Figure 5. The Evolution of Bias (Marie et al., 2020)

These issues (constructed reality, the mangling of messages, and cognitive limitations) form the background for answering the question, why did the reporters give differing accounts to President Trump's press conference.

\section{Cognitive Message Processing and Cognitive Mapping}

The paper now puts together the concepts presented in the background section as we move toward examining our opening question. In this section, the paper offers the concept we term Cognitive Message Processing (CMP) to mean the set of assumptions, represented here by a nomological network, that organizes how messages impact the receiver. The paper introduces a related concept of Cognitive Mapping to represent the current state one's nomological network, which affects and is affected by the CMP.

Nomological Network. As we saw above, the relationship between ideal objects and real objects can be diagrammed as a nomological network. On one side of a nomological network diagram are the real, that is, observable objects and on the opposite side are hypothesized constructs and their hypothesized relationships to other constructs. Figure 6 illustrated the theory substituting "message" for "observation." Here we consider the message in the broadest sense as that which we perceive by sight, hearing, or any other sense or set of senses.

Let us now explore how this concept relates to one's CMP and Cognitive Mapping.

Consider that when we hear music about a songbird, cognitive constructs are activated inside our brains. We may imagine seeing a bird in a tree. The constructs involving birds, birdcalls, and music interact and may lead us to a response, perhaps either to approach and listen more closely or to retreat. The music and our reaction to it exist in the real world as observables; what led us to approach or retreat exists only in our heads as constructs and their interrelationships. CMP and Cognitive Mapping theory assume that a nomological network can explain what is occurring in our brains. If our past experiences with birds have been positive, our cognitive mapping for birds will be quite different than if our past experiences with birds were fearful. 


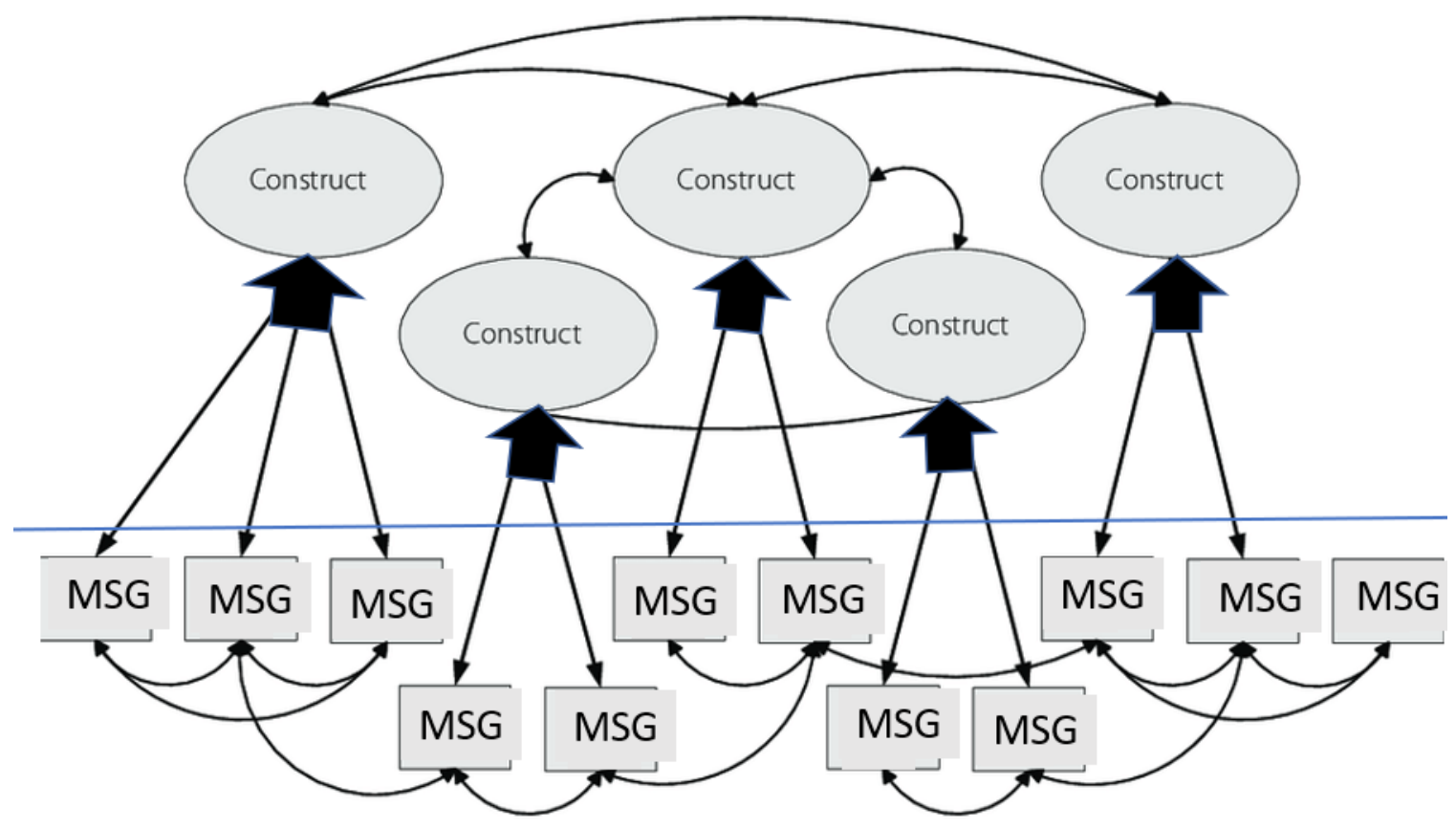

Figure 6. The nomological network showing the Cognitive Map (the constructs and their interrelationships) and Cognitive Message Processing (how the Messages received and the Response) are stored, ignored, or garbled in the Cognitive Map.

\section{Constructed Senses of Reality}

Unlike the idea of science that reality exists independently from our brains, in everyday life people construct their sense of reality individualistically. If a tree falls in a forest and no one hears it, science says it fell, but its collapsing affected no one's cognitive map.

CMP theorized that we construct our ideas of reality in part from the messages we process. In turn, Cognitive Mapping theory posits that we all construct our ideas of reality from the messages we process and have previously processed. Since we each have a different history of messages, we each have individual notions of reality. Here we use the term message in the broadest sense as all that we perceive and attend to. The following example illustrates this concept.

An example: Suppose their employer asks two employees to submit a recommendation about a future employee dining room. The first employee, an environmentalist, using her cognitive map about what is important, chooses to include in her report evidence that advances the use of recyclable materials and pure, natural foods. The second, a gourmet, promotes the advantages to employee morale of serving tasty meals presented with garnish on formal earthenware plates. As in our original Trump reporter example, the same evidence is available to both employees; the values each place on different facts relies on the individual's then-current cognitive map.

Not all messages are truthful: Not all messages we receive represent the truth, the whole truth, and nothing but the truth. Some messages convey non-factual information. For example, some politicians, sellers of used cars, and hucksters utter fabricated messages. In addition to wholesale falsehoods, rumors and unverified stories are among the messages available to the CMP.

In summary, Cognitive Message Processing and Cognitive Mapping occur like a black box, taking in current messages and processing them in light of past messages (and perhaps also other considerations) in the brain. The message may change one's cognitive map. Likewise, one's cognitive map may filter out some messages, for example, due to bias. The outcome of this processing is how the message impacts beliefs and actions and how current beliefs affect the message's reception. See Figure 7. 


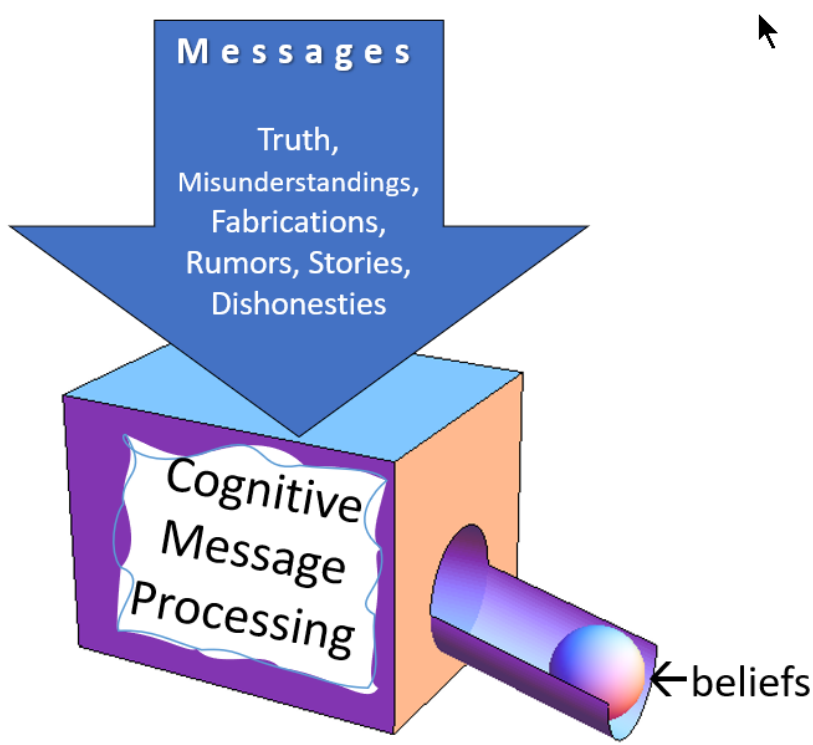

Figure 7. Effect of messages according to some function of the constructs of the cognitive map.

\section{Example of Cognitive Message Processing impact on Cognitive Mapping}

Beliefs about the role of women. Let us consider a real-world example of CMP. Young girls growing up in 1940 might ask themselves, "What will I become in the next 15 years? For toys, I am given dolls while my brother receives toy pistols. In school, I learn home economics when the boys learn carpentry. I understand that boys are better at mathematics and science, so I do not even try to show my aptitude. My role models on TV in programs such as Leave it to Beaver and Father Knows Best are mothers who take care of their family and follow their husband's directions. In the theater, the movies teach me that women in business are secretaries, and men are their bosses. I learned this cognitive map from the messages I receive from my environment, even if no one explicitly explains it to me."

The shared belief about the role of women in society started to change with the publication of Betty Friedan's book "The Feminine Mystique" (1963). The book challenged the then-common cognitive map of women's roles in society. Friedan writes that "fulfillment as a woman had only one definition for American women after 1949 — the housewife-mother." Friedan began her research in 1957 following her survey of those attending her woman's college reunion, which found many to be unhappy with their lives as housewives. Her work served as the seed for a movement seeking equality for women, leading to changes in the legal system, particularly regarding divorce, custody, and domestic violence and rape.

Like the example above, people learn about the values, virtues, ethics, and beliefs of our society from messages about its heroes, both real and mythical. Depending on where and when we live, we might be taught to aspire to be like Hercules, Beowulf, Robin Hood, Jesus, Muhammad, Siddhartha Gautama, or Zoroaster.

\section{DISCUSSION}

So far, the paper has laid out the basis for a theory of cognitive mapping and cognitive message processing. What are some implications of these theories? 


\section{MESSAGE COMPETITION}

As mentioned above, we now live in a time of "data smog" and "information glut" (Shenk, 1997). With so much potential competition for our limited attention, many try to make their message stand out. Advertising, politics, and entertainment, for example, compete for one's eye and ears. Are there qualities that lead to one message to stick more than others?

Given the huge competition, what makes some messages more effective at impacting cognitive maps? That is, what makes messages resonant? That is the topic the paper explores next.

\section{CREATING RESONANT MESSAGES TO OVERCOME MESSAGE COMPETITION}

What characteristics lead to a message impacting the recipient's behavior, fitting with peoples' cognitive maps so that they resonate with them? By resonate, we mean the message passes through the various cognitive filters and biases and attracts the receiver's attention, i.e., they appeal to the receiver in a personal or emotional way.

A message's resonance for any individual depends in part on that individual's cognitive map, including attributes such as prior knowledge, values, and biases. Other message attributes that fit well with cognitive mappings, such as simplicity, surprise, and sex, are also described below.

\section{Cognitive dissonance, cognitive consistency}

There is a tremendous amount of research on the topic of mental representation. One research path is on how the mind works to retain message consistency. Let us first examine Festinger's 1962 cognitive dissonance theory because of its relative simplicity and because it may be already familiar to readers in a variety of fields.

Following Harmon-Jones and Mills (2019, p. 3-6), let us say that a message is consistent with one's existing cognitive map if it fits with the existing mental model and is dissonant if it is incompatible. The authors write:

Dissonance is aroused when people are exposed to information that is inconsistent with their beliefs. If the dissonance is not reduced by changing one's belief, the dissonance can lead to misperception or misinterpretation of the information, rejection or refutation of the information, seeking support from those who agree with one's belief, and attempting to persuade others to accept one's belief. (p.6)

The greater the magnitude of the dissonance, the greater is the pressure to reduce dissonance. ... Dissonance can be reduced by removing dissonant cognitions, adding new consonant cognitions, reducing the importance of dissonant cognitions, or increasing the importance of consonant cognitions. (p. 3)

Festinger et al. (1956) report on a doomsday cult that predicted the end of the world by a flood caused by space aliens. Believers of the cult thought they would be "taken," evacuated to a spaceship, before the calamity as a reward for their being faithful. When the calamity did not occur, the leader of the cult said she received transmissions from outer space that God saved the entire world because of the cult's faith. At that point, some cult members, those who were not with the leader at the doomsday experience, drifted away due to cognitive dissonance. In contrast, those with the leader resolved their cognitive dissonance by proselytizing, seeking to persuade others of the truth of their beliefs. The believers who proselytized created for themselves cognitive consonance by reinterpreting the lack of tragedy as proof of the truth of their religious convictions.

\section{Cognitive consistency, motivated reasoning, and relationships}

The example above illustrates that cognitive map commonality among people comes in part on shared values. As McPherson et al. (2001) write, "Similarity breeds connection. This principle-the 
homophily principle — structures network ties of every type, including marriage, friendship, work, advice, support, information transfer, exchange, comembership, and other types of relationship" (p. 415).

The potential dark side of homophilous cognitive map sharing is intimidation. People's unconscious tendency to credit and dismiss facts independent of the truth to promote some goal or interest is identity-protective cognition (IPC). IPC as motivated reasoning (Kunda, 1990) is a type of motivated reasoning; Sherman and Cohen (2006) write that people display IPC when, to protect their status within the affinity group, they alter their beliefs.

Similarly, Elisabeth Noelle-Neumann (1974) found that out of fear of isolation or reprisal, people tend to remain silent when they feel that their views are in opposition to the majority view. She called this phenomenon the "Spiral of Silence." (For more on the impact of social networks on cognition, see Smith et al., 2020).

\section{Additional factors in message resonance}

Heath and Heath (2007) popularized and summarized how to make ideas that withstand the competition. They summarize their advice on how to construct messages that survive the competition for limited attention capacity in what they call their SUCCESs model.

- S- Simple. Keep the message simple and short. Concise messages that focus on the idea's essence are better since they provide fewer opportunities for filtering out. In this way, less is more.

- $\quad \mathbf{U}$ - Unexpected. Messages that are unexpected garner the most attention. One way to do this is to ask questions to appeal to curiosity. We see this in grocery store tabloids whose headlines might read, "Is the 93-year-old Queen of England pregnant"; "Is she a Martian?".

- C-Concrete. Have the message paint a mental picture that helps people remember it.

- C- Credible. Quote experts or anti-authorities. Interestingly, some messages based on lies claim to be supported by experts.

- E- Emotional. People care about people more than they do about numbers and statistics. Appeal to the person using “What's in It for Me?” For example, a photo of a crying child or a crumbling house appeal to emotion.

- $\quad$ S-Stories. As the authors write, "stories drive action through stimulation (what to do) and inspiration (the motivation to do it)."

Heath and Heath (2007) wrote their book for the popular audience and provided simple guidelines. Another book which summarizes his academic literature as well as others was written by Robert Cialdini (2016). He has devoted his academic career to the topic of how to persuade and influence. $\mathrm{He}$ is conversant with the psychology and marketing research findings of others on this topic. In the context of this paper, one can view his book Pre-suasion as ways to package a message to increase its potency and attract attention. While it is not possible to summarize his $300+$ page book here, below are just a few salient points not covered above.

- Keep the clients focused on your message, and it will become vital for them, at least for a short time. (We see this in campaigns and propaganda that keep repeating the same idea.)

- Once you have initial buy-in for the message from the client, getting the client to commit, for example, by pledging or donating, can preserve the message in his cognitive map. (US politicians request the smallest of donations. Once you have any buy-in, you have an entree to that person's cognitive map and can ask for more.)

- For some messages, violence and sex attract attention. Images of crying children or breasts attract many eyes. 


\section{Phrasing matters: Words and power of connotation and ambiguity}

"Since we cannot change reality, let us change the eyes which see reality."

- Nikos Kazantzakis (source: https://en.wikiquote.org/wiki/Nikos Kazantzakis)

When telling a story, Carver et al. (1983) show how the selection of wording can have a significant impact on informing. For example, people prefer to purchase a "pre-owned" car than to buy a "used" car. Retitling the estate duty as a "death" tax makes many loyal taxpayers less enthusiastic about sharing their unearned wealth.

From medical research and brain science, Newberg and Waldman (2013, p. 3) write, "a single word has the power to influence the expression of genes that regulate physical and emotional stress." Positive words like "love" build resilience in the brain; hostile language disrupts the production of neurochemicals that protect us from stress. The book notes the following:

By holding a positive and optimistic thought in your mind, you stimulate frontal lobe activity. This area includes specific language centers that connect directly to the motor cortex responsible for moving you into action.... And as our research has shown, the longer you concentrate on positive words, the more you begin to affect other areas of the brain. Functions in the parietal lobe start to change, which changes your perception of yourself and the people you interact with. A positive view of yourself will bias you toward seeing the good in others, whereas a negative self-image will incline you toward suspicion and doubt. Over time the structure of your thalamus will also change in response to your conscious words, thoughts, and feelings, and we believe that the thalamic changes affect the way in which you perceive reality. (pp. 34-35)

Psycholinguists also research the issue of words and the brain. Danziger and Ward (2010) found that words activate associations (also called connectionist processes), and even the selection of spoken language impacts decision making.

\section{Wording matters: Ambiguity}

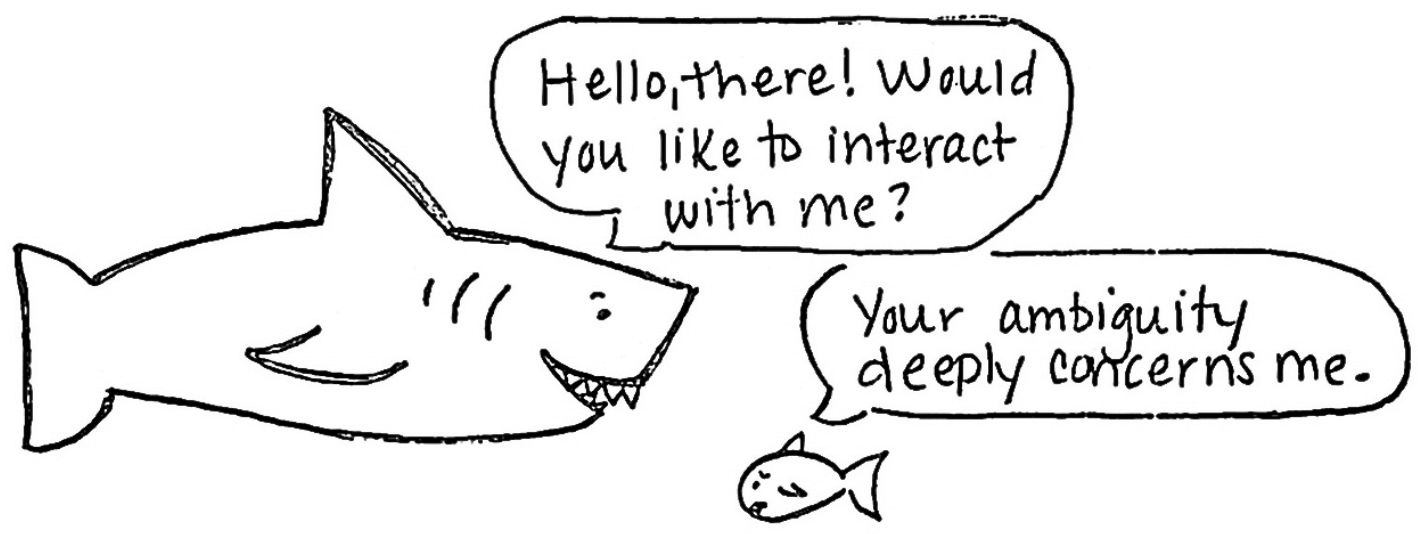

Figure 8. What does the shark mean by "Interact"? Source: Google images labeled for reuse

Boyarskaya (2019) points out that ambiguity provides an additional layer to meaning beyond denotation and connotation. Commonly, politician pepper their rhetoric with words that appeal to most people, like peace and prosperity. Doing so enables the message to get through the filters of people's cognitive mapping and develop their trojan horse message. For example, the charmer Louis Farrakhan started his talk to women about women by pointing out their value. Only later did his message emerge that the role of women is to put their husbands above their careers. "Your professional lives can't satisfy your soul like a good, loving man" ("Facing Complaints of Bias," 1994). Similarly, a 
common motif of the USSR was to portray itself as peace-loving (Bukovsky, 1982). This tactic led to the acceptance of its messages by useful idiots as well as fellow travelers who use ambiguity to solicit support for their position. See Figure 8.

\title{
Wording matters: Framing
}

"Facts are one thing. And the way that people react to them and make evaluations is entirely different.", says Isaiah Arkin, a professor of Structural Biochemistry at the Hebrew University of Jerusalem, in an interview with David Horovitz (2020). In the interview, Arkin related the following anecdote on the psychology of decision making used by Nobel Prize winner Daniel Kahneman from the Hebrew University.

Someone goes to a doctor with a particular problem. The doctor tells him, "oh, fantastic; I have a procedure that will cure this by 90 percent." The patient says, "Excellent procedure — sure. Sign me up."

That individual might choose to go to a different doctor. And that different doctor might say, oh, I have a procedure, but there's a 10 percent failure. The patient says, "That's a terrible procedure. Why would I use that?"

Tversky and Kahneman's 1989 Framing Theory tells us that when given alternatives, the choice phrasing impacts to a great extent how well that choice-message will be accepted.

Like framing, wording can trigger the metaphor's construct in one's cognitive map.

\section{Wording that invokes Metaphors create message resonance}

\author{
"If you want to change the world, you have to change the metaphor." \\ Joseph Campbell (quoted by Bill Moyers, 2017).
}

While all have their own specific sets of cognitive maps, myths, and other common sets of shared beliefs, there are elements common across many cognitive maps. Myths, whether based on facts or unproven stories, form the backdrop for the metaphor.

An empirical study by Thibodeau et al. (2017) demonstrates the power of the metaphor. They asked subjects the solution to a real-world problem, changing just one word. The choice of which specific word, beast, or virus, changed the metaphor subjects used in calculating the best solution. Subjects read the following:

Crime is a [beast/virus] ravaging the city of Addison. Five years ago, Addison was in good shape, with no obvious vulnerabilities. Unfortunately, in the past five years, the city's defense systems have weakened, and the city has succumbed to crime. Today, there are more than 55,000 criminal incidents a year - up by more than 10,000 per year. There is a worry that if the city does not regain its strength soon, even more serious problems may start to develop.

Those whose paragraph included the word beast were more in favor of incarceration. Those reading the word virus were inclined more toward treatment. An out of control monster needs to be captured and locked away, but spreading infection requires thoughtful analysis to determine and then eliminate its root causes. So, changing just one word activated different mental constructs in the cognitive map and so stimulated different solutions.

Typically, people do not even notice the metaphor elicited, and so do not realize the great impact it has on them. The selection of the wording may elicit in one's cognitive map a shortcut that directs attention into one area for a solution and thus away from others. Notice something unusual in the above case. The single word change did not attract attention.

Goodhew and Kidd (2020) show that even the color of the word on the page or screen affects behavior. This finding fits well with Galdi et al.'s (2008) theory that automatic mental associations affect decision making. 
It appears that messages act upon us both consciously and subconsciously. Do we have two minds?

\section{Inside the cognitive message processor: Memories and values}

Kahneman (2011) writes that most of our thinking relies on hidden assumptions in a robot-like fashion. Kahneman suggests we can conceive of thinking as our having two brains: our slow, rational thinking brain, and another, our more robot-like brain which he calls System 1 that relies on typically uncontested assumptions. System 1 is fast, automatic, intuitive, and mostly unconscious. System 1 uses associations and metaphors to quickly produce our sense of what is real.

What are the elements of the cognitive map? Certainly, memories, both real and constructed, are elements. Another element is one's values. The role of values in determining outcomes has been studied for many years and in many disciplines, including law (see McDougal, 1952), education (Raths et al., 1966), and therapy and counseling (Tafee, 1976). Values come from messages and memories received from the community, the family, the culture, politicians, and personal life experiences.

We can understand values in the present context as the constructs in cognitive map theory. For example, a message regarding the state closing abortion clinics will be valued by those who oppose abortions differently than those who support it. In many cases, the issue is not right vs. wrong, but rights vs. rights. Another value example is, "should government regulations be limited to encourage free enterprise, or should they be expanded to protect citizens from business abuse?"

Non-cognitive-based characteristics. In addition to the cognitive characteristics that affect message resonance, there are non-cognitive characteristics that play a role. One is timing. A message will be best attended to when there is less competition for one's attention. At the extreme, messages received while one is asleep or fatigued will have less impact.

\section{CONCLUSION}

We all are bombarded daily with more messages than any brain could handle. Humans developed a way to filter messages to direct attention and memory to those that seem important.

The theory of the cognitive maps speculates that our actions, thoughts, and decisions are driven by sets of assumptions, mostly hidden, that we term our cognitive map. The cognitive map affects not only what messages affect us, but also what messages we elicit and what message we share.

Let us return to the quandary that started this paper. Why did the various reports of Trump's interaction with a reporter produce different headlines? The theory of cognitive maps says that this is because the reporters applied different assumptions about Trump. In their cognitive maps, Trump may be valued with attributes of hero (by right-leaning outlets) or impediment to a free press (by left-leaning outlets). Each attribution colors how the reporter saw reality.

\section{LIMITATIONS}

This paper is just the start in theory building and testing. It starts by bringing together diverse fields to bear on the question, yet more and testable research is needed. But this paper is limited in what it has covered. Its model is, at present, quite abstract and hard to quantify, much less test. And its coverage of some fields is superficial.

For example, on the role of word choice, the field of semantic infiltration is ripe for greater exploration. Speechwriters, for example, delve deeply into how to express ideas to increase their impact.

The field of non-verbal messages requires study. Music, sounds, dance, art, architecture, and such provide messages and are not yet well understood.

The areas of information, misinformation, and disinformation are not well covered in this paper. Disinformation as an academic study is well developed in Russian academies but not well understood by Western academics. 


\section{FUTURE RESEARCH}

The study of informing is truly transdisciplinary. Future research is needed to locate additional fields of study in addition to psychology, brain science, and such whose research findings may add to the study of cognitive mapping. For example, the inner working of the cognitive mapping may be similar to the Simple Recurrent Neural Network model used by Rumelhart et al. (1986) to describe memory, or cognitive research related to social dynamics, and trust calibration such as Aarøe and Petersen (2020) or Blank (2020). Likewise, the model can be connected to research on misinformation and groups along the lines of Kahan (2017) and Kahan et al. (2007). Viewing such isolated discipline-specific research in terms of the transdisciplinary informing process will add relevance and depth both to the theory of cognitive mapping and to the client discipline.

A second area for future activity is to publish empirical studies showing the efficacy of the model offered here. Such research might offer ideas on how to parameterize the connections between the constructs and their interconnecting paths. Indeed, many journal pages are filled with the parameterization of such path analyses.

\section{REFERENCES}

Aarøe, L. \& Petersen, M. B. (2020) Cognitive Biases and Communication Strength in Social Networks: The Case of Episodic Frames. British Journal of Political Science, 50(4), 1561-1581. https://doi.org/10.1017/S0007123418000273

Blank, D. S. (2020). Learning to see analogies: A connectionist exploration. arXiv preprint arXiv:2001.06668.

Boyarskaya, E. (2019). Ambiguity matters in linguistics and translation. Слово. pу: балтийский акцент, 10(3), 8193. https://www.researchgate.net/publication/335824581 Ambiguity matters in linguistics and translation

Bukovsky, V. (1982). The peace movement and the Soviet Union. Quadrant, 26(12), 12. https://jmw.typepad.com/files/bukovsky---peace-movement-and-ussr.pdf

Carver, C. S., Ganellen, R. J., Froming, W. J., \& Chambers, W. (1983). Modeling: An analysis in terms of category accessibility. Journal of Experimental Social Psychology, 19(5), 403-421. https://doi.org/10.1016/00221031(83)90019-7

Cialdini, R. (2016). Pre-suasion: A revolutionary way to influence and persuade. Simon and Schuster.

Cronbach, L. J., \& Meehl, P. E. (1955). Construct validity in psychological tests. Psychological Bulletin, 52(4), 281302. https://doi.org/10.1037/h0040957

Danziger, S., \& Ward, R. (2010). Language changes implicit associations between ethnic groups and evaluation in bilinguals. Psychological Science, 21(6), 799. https://doi.org/10.1177/0956797610371344

Eden, C. (1988). Cognitive mapping. European Journal of Operational Research, 36(1), 1-13. http://reports-archive.adm.cs.cmu.edu/anon/anon/usr/ftp/usr0/ftp/1997/CMU-CS-97-166.pdf

Facing complaints of bias, Farrakhan speaks to women only. (1994, July 31). The New York. Times, Section 1, p. 32. https://www.nytimes.com/1994/07/31/us/facing-complaints-of-bias-farrakhan-speaks-to-womenonly.html

Festinger, L. (1962). A theory of cognitive dissonance (Vol. 2). Stanford University Press

Festinger, L., Riecken, H., \& Schachter, S. (1956). When Prophecy Fails. University of Minnesota Press. https://doi.org/10.1037/10030-000

Friedan, B. (1963). The feminine mystique. W. W. Norton

Galdi, S., Arcuri, L., \& Gawronski, B. (2008). Automatic mental associations predict future choices of undecided decision-makers. science, 321(5892), 1100-1102. https://doi.org/10.1126/science.1160769

Gill, T. G., \& Hoppe, U. (2009). The business professional doctorate as an informing channel: A survey and analysis. International Journal of Doctoral Studies, 4(1), 27-57. 
Goodhew, S. C., \& Kidd, E. (2020). Bliss is blue and bleak is grey: Abstract word-colour associations influence objective performance even when not task relevant. Acta Psychologica, 206, 103067. https://doi.org/10.1016/j.actpsy.2020.103067

Hains, T. (2020, March 20). President Trump upbraids NBC’s Peter Alexander: "You should be ashamed of yourself." RealClear Politics. https://www.realclearpolitics.com/video/2020/03/20/president trump upbraids nbcs peter_alexander_you should be ahamed of yourself.html

Harmon-Jones, E., \& Mills, J. (2019). An introduction to cognitive dissonance theory and an overview of current perspectives on the theory. https://doi.org/10.1037/0000135-001

Heath, C., \& Heath, D. (2007). Made to stick: Why some ideas survive, and others die. Random House.

Holz, R. (2020, July 14). Different wavelengths: Science finds hummingbirds see ultraviolet light invisible to humans. Wall Street Journal. http://wsj.com/articles/different-wavelengths-science-finds-hummingbirdssee-ultraviolet-light-invisible-to-humans-11594688179

Horovitz, D. (2020, March 18). Israeli scientist: You're not going to see millions of people die from COVID19. The Times of Israel. https://www.timesofisrael.com/israeli-scientist-youre-not-going-to-see-millions-ofpeople-die-from-covid-19/

Jamieson, K., \& Hyland, P. (2006). Good intuition or fear and uncertainty: The effects of bias on information systems selection decisions. Informing Science: The International Journal of an Emerging Transdiscipline, 9, 49-69. https://doi.org/10.28945/471

Kahan, D. M. (2017). Misconceptions, misinformation, and the logic of identity-protective cognition. Understanding and Addressing the Disinformation Ecosystem workshop. Annenberg School for Communication. https://doi.org/10.2139/ssrn.2973067

Kahan, D. M., Braman, D., Gastil, J., Slovic, P., \& Mertz, C. K. (2007). Culture and identity-protective cognition: Explaining the white-male effect in risk perception. Journal of Empirical Legal Studies, 4(3), 465-505. https://digitalcommons.law.yale.edu/cgi/viewcontent.cgi?article $=1100 \&$ context $=$ fss papers

Kahneman, D. (2011). Thinking, fast and slow. Macmillan.

Kunda, Z. (1990). The case for motivated reasoning. Psychological Bulletin, 108(3), 480. https:// fbaum.unc.edu/teaching/articles/Psych-Bulletin-1990-Kunda.pdf

Lebowitz, S. \& Lee, S. (2015, August 26). 20 cognitive biases that screw up your decisions. Business Insider. https://amp.businessinsider.com/cognitive-biases-that-affect-decisions-2015-8

Liedke, L. (2020, April 7). 100+ Internet Statistics and Facts For 2020. Website Hosting Rating. https://www.websitehostingrating.com/internet-statistics-facts/

MacCorquodale, K., \& Meehl, P. E. (1948). On a distinction between hypothetical constructs and intervening variables. Psychological Review, 55, 95-107. https://doi.org/10.1037/h0056029

Marie, A., Altay, S., \& Strickland, B. (2020). The cognitive foundations of misinformation on science. Embo Reports, 21(4). https://doi.org/10.15252/embr.202050205

McDougal, M. S. (1952). The comparative study of law for policy purposes: Value clarification as an instrument of democratic world order. Yale Law Journal, 61, 915. https://digitalcommons.law.yale.edu/cgi/viewcontent.cgi?article $=3483 \&$ context $=$ fss papers

McPherson, M., Smith-Lovin, L., \& Cook, J. M. (2001). Birds of a feather: Homophily in social networks. $A n$ nual Review of Sociology, 27(1), 415-444. https://doi.org/10.1146/annurev.soc.27.1.415

Miller, G. A. (1956). The magical number seven, plus or minus two: Some limits on our capacity for processing information. Psychological Review, 63(2), 81. https://doi.org/10.1037/h0043158

Moyers, B. (2017, June 9). A Conversation with Bill Moyers. Public Broadcasting Service. https://archive.org/details/KQED 20170609090000 A Conversation With Bill Moyers

Newberg, A., \& Waldman, M. R. (2013). Words can change your brain: 12 conversation strategies to build trust, resolve conflict, and increase intimacy. Penguin. 
Nikos Kazantzakis. (n.d.) In Wikiquote. https://en.wikiquote.org/wiki/Nikos_Kazantzakis

Noelle-Neumann, E. (1974). The spiral of silence: A theory of public opinion. Journal of Communication, 24(2), 43-51. https://doi.org/10.1111/j.1460-2466.1974.tb00367.x

Raths, L. E., Harmin, M., \& Simon, S. B. (1966). Values and teaching: Working with values in the classroom. Merill.

Robbins, J. (2014). Manufactured memories. Berkeley Scientific Journal, 18(2). https://escholarship.org/content/qt1jm7m8dh/qt1jm7m8dh.pdf

Rossignac-Milon, M., Pinelli, F., \& Higgins, E. (2020). Shared reality and abstraction: The social nature of predictive models. Behavioral and Brain Sciences, 43, E145. https://doi.org/10.1017/s0140525x19003212

Rumelhart, D. E., Hinton, G. E., \& Williams, R. J. (1986). Learning representations by back-propagating errors. Nature, 323(6088), 533-536. http://www.cs.toronto.edu/ hinton/absps/naturebp.pdf

Shenk, D. (1997). Data smog: Surviving the information glut. HarperCollins Publishers.

Sherman, D. K., \& Cohen, G. L. (2006). The psychology of self-defense: Self-affirmation theory. Advances in Experimental Social Psychology, 38, 183-242. http://www.dagankenaz.com/framing/ShermanDK SelfAffirmationTheory2006.pdf

Simons, D. J., \& Chabris, C. F. (1999). Gorillas in our midst: Sustained inattentional blindness for dynamic events. Perception, 28(9), 1059-1074. https://doi.org/10.1068/p281059

Smith, E. B., Brands, R. A., Brashears, M. E., \& Kleinbaum, A. M. (2020). Social networks and cognition. Annual Review of Sociology, 46. https://doi.org/10.1146/annurev-soc-121919-054736

Taffee, S. J. (1976). Values clarification ten years later: Changes and futures as perceived by selected experts [Doctoral Dissertation]. Michigan State University. https://fedcom4a.lib.msu.edu/etd/44281/datastream/OBJ/Down$\underline{\operatorname{load} /}$

Thibodeau, P. H., Hendricks, R. K., \& Boroditsky, L. (2017). How linguistic metaphor scaffolds reasoning. Trends in Cognitive Sciences, 21(11), 852-863. https://nmekenna.me/papers/metaphor scaffolding.pdf https://doi.org/10.1016/j.tics.2017.07.001

Trochim, W. M. K. (2020). What is the nomological net? Research methods knowledge base. https://conjointly.com/kb/nomological-network/

Tree swing cartoon pictures. (n.d.) BusinessBalls. https://www.businessballs.com/amusement-stress-relief/tree-swing-cartoon-pictures-early-versions/

Tversky, A., \& Kahneman, D. (1989). Rational choice and the framing of decisions. In B. Karpak \& S. Zionts (Eds.), Multiple criteria decision making and risk analysis using microcomputers (pp. 81-126). Springer, Berlin, Heidelberg. https://doi.org/10.1007/978-3-642-74919-3 4

Yanes, J. (2017). Things that animals perceive about the world that we humans don't. OpenMindBBVA. https://www.bbvaopenmind.com/en/science/bioscience/things-that-animals-perceive-about-the-worldthat-we-humans-dont/ 


\section{BIOGRAPHY}

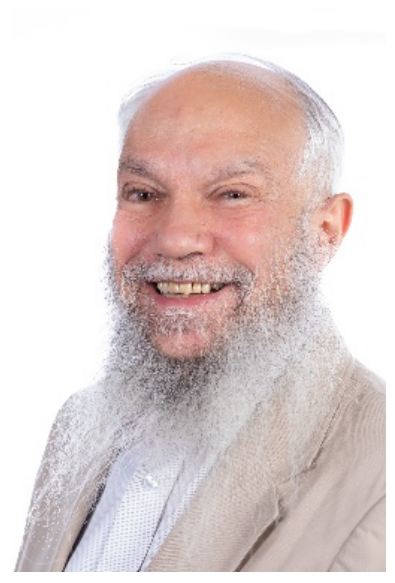

Eli Cohen founded and now serves as the Executive Director of the Informing Science Institute and as Editor-in-Chief of two of its journals, Informing Science: the international journal of an emerging transdiscipline, and the journal Issues in Informing Science and Information Technology. He has a background in multiple disciplines, including psychology, statistics, business, and cat tending. He retired from the Kozminski University in Warsaw. 